\title{
NANOPARTICLES AS A NEW APPROACH FOR TREATING HYDATID CYST DISEASE
}

\author{
Bushra H. Shnawa ${ }^{1,2}$ *, Shereen J. Al-Ali3 , and Sara O. Swar ${ }^{4}$ \\ 'Department of Biology, Faculty of Science, Soran University, Kurdistan, Iraq \\ ${ }^{2}$ Scientific Research Center, Soran University, Kurdistan-Iraq \\ ${ }^{3}$ Departments of Pathological Analyses, College of Science, University of Basrah, Basrah, Iraq \\ ${ }^{4}$ College of Agricultural Engineering Sciences, Salahaddin University, Kurdistan, Iraq \\ *Corresponding author: Bushra.shnawa@soran.edu.iq
}

\section{INTRODUCTION}

Hydatidosis or Cystic Echinococcosis (CE) is a zoonotic disease resulting from Echinococcus granulosus metacestode infection. Several investigations described it as an emerging or re-emerging infection, with high medical and economic impacts in many countries (Moro and Schantz 2009; Eckert e al. 200o). Also, it is classified as a neglected tropical illness (WHO 2001). The disease is endemic in rural sheep-raising areas, where dogs consume the infected animal organs. In Iraq, the disease is considered hyperendemic, with high socio-economic outcomes owing to the infection of both humans and their livestock (Benyan et al. 2013). Sadjjadi (2006) reported an increasing trend in CE cases in North Africa, Middle East, and Iraq. Three techniques for curing the Echinococcosis infection of liver are known; these include operation, percutaneous aspiration, and chemotherapy (Adas et al. 2009). Surgical procedure remains the primary therapeutic method for $\mathrm{CE}$, but other procedures may play an efficient role in its management (Pitt and Pitt 2013). Leakage of cystic fluid rich with protoscoleces is the leading cause of recurrence; therefore, scolicidal materials are used for inactivating the protoscoleces during surgical operation. However, these materials have many adverse effects (Shi et al. 2016).

Hypertonic saline is applied as protoscolicidal material now-a-days. Still, it causes hypernatremia, which in turn, results in convulsions, intracranial hemorrhages, necrosis and degeneration, and myelinolysis (Albi et al. 2002; Adas et al. 2009). Benzimidazole is the main therapeutic agent used for CE therapy. Unfortunately, it shows several side effects, such as leucopenia, alopecia, liver toxicity, and thrombocytopenia (Junghanss et al. 2008), as has been shown in Table 1.

Additionally, Benzimidazole is characterized by its reduced water solubility, which results in its low bioavailability. Consequently, low gastrointestinal absorption leads to insufficient systemic availability and reduced efficacy against CE (Evrard 2002). For this reason, many experimental studies were conducted to increase the effectiveness of albendazole. Among these, Shuhua et al. (2002) prepared this medication in soybean oil emulsion and tested it in murine Echinococcosis. In addition, new plans were tested to determine novel protoscolicidal green synthesized compounds from these plants. In this regard, Kohansal et al. (2017) reviewed the publications published from 1996 to 2015 and concentrated on the plant extracts that exhibited significant protoscolicidal effectiveness. Moreover, the protoscolicidal properties of Curcuma longa, Zingiber officinale, and Cyperus rotundus extracts were examined (Almalki et al. 2017; Shnawa et al. 2017). The findings revealed the possible efficacy of these plant extracts against Echinococcosis.

Nanoparticles (NPs) possess a broad choice of applications, especially in the medical aspect, which show significant signs of progress in developing different methods for improving drug ability, drug distribution, diminishing toxicity of medications, and allowing the programmed nanomaterial production (Rai et al. 2017). This chapter highlights the NPs, mainly focused on the greenish biosynthesis processes. Besides, it explains the protoscolicidal ability of NPs by reviewing the most recent published papers concerning this aspect. These studies may permit the discovery of an innovative healing alternative for hydatid cyst disease.

\section{Classification of Echinococcus granulosus}

Previously, E. granulosus was considered one species of a broad genotypic and phenotypic differences, whereas now it is recognized as a group of cryptic species that vary in shape, growth, host specificity, and ability to infect humans. Also, variation in mitochondrial and nuclear genes has created phylogenetic trees and propositions of different taxa ancestries. Recent studies have molecularly subdivided this species into E. granulosus sensu stricto (includes G1-3), E. felids (priorly 'lion strain'), E. equinus ('horse strain,' genotype $\mathrm{G}_{4}$ ), E. ortleppi ('cattle strain,' genotype $\mathrm{G}_{5}$ ) and E. canadensis. The last one displays the most comprehensive diversity, and it includes 'camel strain' of genotype G6, 'pig strain,' related to genotype $\mathrm{G}_{7}$, along-with double 'cervid strains,' G8 and Gio (Romig et al. 2015). In this regard, and most recently, nucleotide sequence alignments of mitochondrial cytochrome c oxidase subunit 1 (coxl) gene were performed for characterizing the liver hydatid cysts of sheep and cows in Iraq. The finding showed that all samples belonged to the G1 sheep strain (Abdulla et al. 2020).

Based on the reports of Thompson (1986), Rausch (1997), and Roming et al. (2015), E. granulosus belongs to the following classification:

Phylum: Platyhelminthes. 
Superclass: Eucestoda.

Class: Cestoidea.

Subclass: Cestoda.

Order: Cyclophyllidea Ben; Braun, 1900.

Family: Taeniidae Ludwig, 1886.

Genus: Echinococcus Rudolphi, 1801.

Species: Echinococcus granulosus Batsch, 1786

\section{Life cycle of Echinococcus granulosus}

Dual vertebrate hosts are needed for completing the life cycle of Echinococcus granulosus. Protoscoleces play an avital role in initiating the life cycle of this parasite because it is the infective stage for the carnivores (dogs), representing the final host (Galindo et al. 2008). The Echinoccocal worms attach to the mucosa of the small intestine of dogs and produce eggs. The eggs can infect humans and other susceptible herbivores, like sheep and cattle (Walker et al. 2004). Humans can be infected by accidental consumption of the embryonated eggs and are known as closed way hosts for Echinococcosis. After their consumption by the intermediate host, eggs hatch releasing the embryos that penetrate the mucosa and then find their way via blood or lymph to the liver, lungs or to other sites to produce unilocular fluid-filled hydatid cysts. When the definitive hosts consume viscera of infected animals with the metacestodes, the protoscoleces evaginate, attach to the mucosal lining of their intestine and grow into the worm stage (Fig. 1).

\section{Hydatid Cyst Structure}

The hydatid cyst structure of E. granulosus contains three layers: i) the external pericyst originates from host cells and produce a fibrous, protective tissue; ii) then comes the laminated membrane (exocyst layer), which is noncellular and permits the semi permeability of nutrients; and iii) the internal germinal layer (endocyst), where the brood capsules are produced. A fully developed cyst contains brood capsules with protoscoleces and is filled with clear fluid, which is rich in daughter cysts and protoscoleces, as shown in Fig. 2 (Eriksen and Agopian 2017; Fritsche and Pritt 2017).

\section{Treatment of Cystic Echinococcosis}

Surgical treatment is the chief therapeutic method for Cystic Echinococcosis, and still, it is the standard gold procedure for large hydatid cysts. Despite the progress of the surgical technique, secondary Echinococcosis due to the leakage of protoscoleces may occur throughout the operation. Such re-occurrence was documented in $\mathbf{2 - 2 5} \%$ of patients (Ammann and Eckert 1996; Eriksen and Agopian 2017). Also, the potent anaphylactic reaction is an additional risk. Consequently, application of some protoscolicidal agent is necessary due to cyst fluid dissemination risk (Pawlowski 1997). An innovative technique that was applied includes Puncture, Aspiration, Injection, and Re-aspiration (PAIR). This procedure starts with the percutaneous puncture of the cyst under ultrasonic guidance, followed by cyst hydatid fluid aspiration, injection of protoscolicidal substance (such as ethyl alcohol), then re- aspiration of the fluid in the next twenty minutes. This method attackes the germinal layer, reducing the cyst. Lastly, collapsing and solidifying of the hydatid cyst takes nplace (Hemphill et al. 2007; Eriksen and Agopian 2017).

Several experimental studies within animal models have established the chemotherapeutics of Echinococcosis. Albendazole and mebendazole are proved to possess the same efficacy (Walker et al. 2004), with mild adverse properties (Table 1). Surgical intervension has some limitations, like recurrence of hydatid cysts. Moreover, it is not applicable for inactive symptomless and tiny hydatid cysts (Brunetti et al. 2010).

\section{Nano-medicine}

The word nano is derived from the Greek words "Nanos" for "dwarf." It equally indicates one billionth part $\left(10^{-9}\right)$. 'Nanoparticles' is defined by the American Society Testing and Materials as particles with a minimum double or extra dimension with a size of 1-100 nm (Alanazi et al. 2010). Dual alternative styles for metallic NPs production include the "bottom-up" way and the "top-down" method (Kaushik et al. 2010). These techniques create nanomaterials which differ from their original material in surface-related characteristics or quantum amount (Roduner 2006). Moreover, nanotechnology represents an expanding research area and a hopeful arena due to its application in diverse scientific research disciplines (Dutta et al. 2017).

Nanomedicine includes biological and non-biological medicinal products. Biological nanomedicines are prepared from biological sources, whereas non-biological ones are called non-biological complex drugs (NBCD), and they are manufactured from different synthetic structures (Mühlebach 2018). The nanomedical products express an extensive variation in their type and structure and have been used in many remedies for acute and chronic diseases. Also, differences in toxicity, solubility, and bioavailability characters are modified by nanotechnology in medicine (Soares et al. 2018).

Disadvantages of nanoparticles include their high cost and potential risks for the human body. Consequently, biological methods, for instance, utilizing microorganisms (Li et al. 2012) and enzymes (Rangnekar et al. 2007), are advised as possible eco-friendly choices for the purpose. Nanomedicine advantages include high bioavailability and stability, diverse administration ways, organized release, and negligible toxicity. In contrast, the disadvantages consist of ethical worries, their costeffectiveness and associated risks (Aditya et al. 2013). In their paper concerning nanotechnology and hepatic illnesses, Reddy and Couvreur (2011) have pointed out that nanomedicines are habitually used phospholipids (such as liposomes), polymers, or iron resources (like minor Fe O Nanoparticles). In a previous investigation, Alving et al. (1978) applied liposomes to increase the effectiveness of medications with Leishmania donovani in 
experimentally infected hamsters. Also, nanobiotechnology is a part of nanotechnology that presents NPs production for particular applications with minimum risk influences from bio-systems resources. Nanobiotechnology is a wide-ranging term, covering the creation and subsequent utilization of particles smaller than 100 nm size (Ahmad et al. 2003). Various organisms, including, plants, algae, filamentous fungi, yeast, bacteria, and viruses, could be considered as sources for NPs production. Some researchers studied the use of microorganisms as potential eco-friendly materials to synthesize NPs, for instance, cadmium, gold sulfide and silver (Mukherjee et al. 2002; Ahmad et al. 2003). Green biosynthesis is recommended now-a-days; it depends on plants and their extracts for generating the NPs (Begum et al. 2009). Among these, leaves extract of black tea has capability to release gold and silver NPs, which is attributed to the presence of polyphenols in the black tea plant (Begum et al. 2009). Nanoparticles produced by plants are more stable, and their synthesis is quicker than that of microorganisms. Also, the NPs are more varied in shape and size than those created by other organisms (Iravani 2011).

Furthermore, AuNPs synthesized by green vegetative were more stable than NPs created by other techniques. Plants contain many phytochemical materials, like terpenes, polyphenols, carboxyl, hydroxyl, and aldehyde functional groups, that can reduce gold salt $\mathrm{HAuCl}_{4}$ to AuNPs (Chanda et al. 2011). Their outcomes emphasized the ability of non-toxic cinnamon -Au NPs as a signal for identifying cancerous cells, which possibly would be clinically advantageous for diagnosis of the disease (Chanda et al. 2011).

Bacteria, Actinomycetes, and fungi were examined to produce metal NPs (Singh et al. 2016). Enzymes from bacteria and phytochemicals of plants with antioxidant activities or reducing characteristics are accountable for reducing metal materials into NPs (Durán et al. 2011).

Table 1: Anti-Echinococcosis drugs with adverse effects.

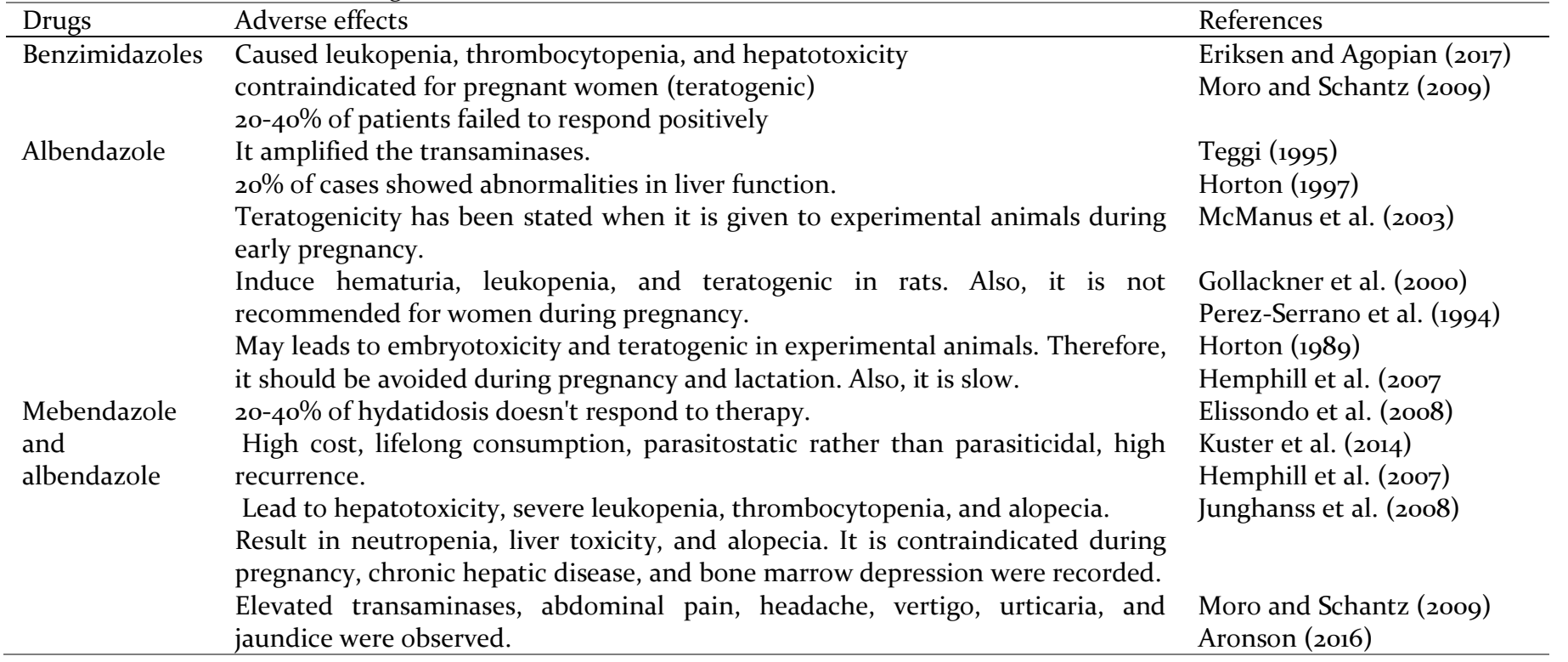

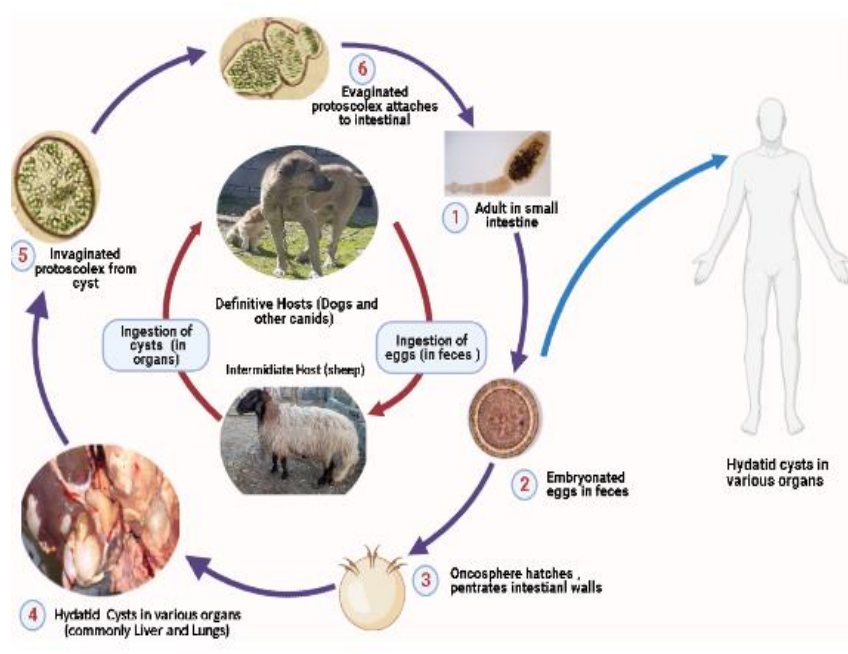

Fig. 1: The life cycle of Echinococcus granulosus.

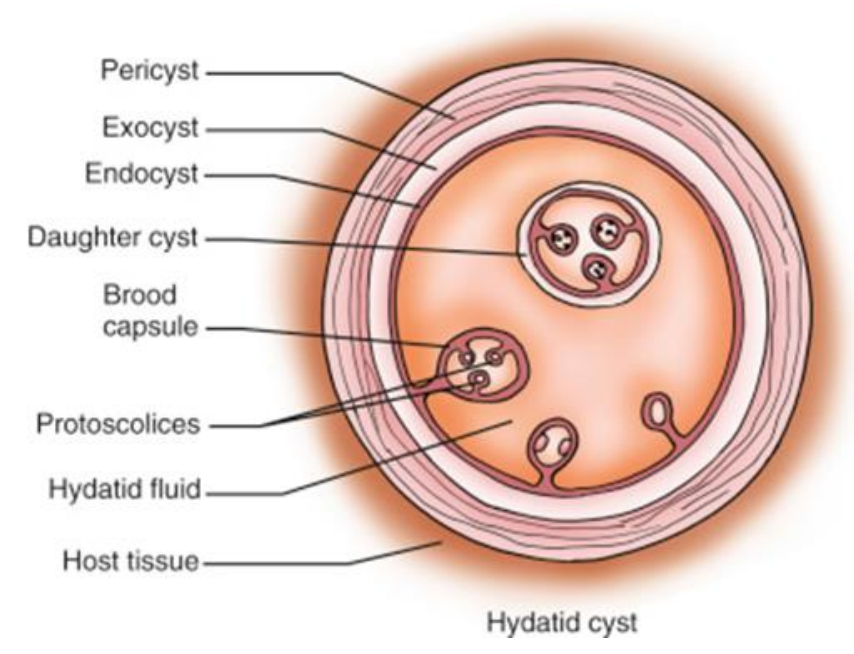

Fig. 2: Schematic diagram of Echinococcal cyst structure, illustrating the pericyst, exocyst, endocyst, and protoscolices of E. granulosus (Eriksen and Agopian 2017). 
Table 2: Scolicidal efficacy of nanoparticles according to some recently published articles.

\begin{tabular}{|c|c|c|c|c|c|c|}
\hline Compound & DIsease & $\begin{array}{l}\text { Experimental } \\
\text { design }\end{array}$ & Dosage & $\begin{array}{l}\text { Treatment } \\
\text { period }\end{array}$ & Efficacy assessment & References \\
\hline Selenium N.P.s & $\mathrm{CE}$ & In vitro & $500 \mathrm{mg} / \mathrm{ml}$ & 10 minutes & $100 \%$ & $\begin{array}{l}\text { Mahmoudvand et } \\
\text { al. (2014) }\end{array}$ \\
\hline Silver NPs & CE & In vitro & $0.15 \mathrm{mg} / \mathrm{ml}$ & 120 minutes & $90 \%$ & $\begin{array}{l}\text { Rahimi et al. } \\
\text { (2015) }\end{array}$ \\
\hline Colloidal silver & $\mathrm{CE}$ & In vitro & $4 \mathrm{mg} / \mathrm{ml}$ & 60 minutes & $71.6 \%$ & $\begin{array}{l}\text { Lashkarizadeh et } \\
\text { al. (2015) }\end{array}$ \\
\hline Gold NPs & $\mathrm{CE}$ & In vitro & $0.3 \mathrm{mg} / \mathrm{ml}$ & 120 minutes & $94 \%$ & $\begin{array}{l}\text { Barabadi et al. } \\
(2017)\end{array}$ \\
\hline $\begin{array}{l}\text { Solid lipid NPs } \\
\text { Loaded on } \\
\text { albendazole sulfoxide }\end{array}$ & CE. & In vivo & $\begin{array}{l}0.5 \mathrm{mg} / \mathrm{kg} \text { BID } \\
2 \mathrm{mg} / \mathrm{kg}\end{array}$ & $\begin{array}{l}\text { Every } 48 \mathrm{hr} \\
\text { for } 15 \text { days }\end{array}$ & Economic \& shortening time & $\begin{array}{l}\text { Ahmadnia et al. } \\
(2013)\end{array}$ \\
\hline $\begin{array}{l}\text { Chitosan albendazole } \\
\text { NPs }\end{array}$ & $\mathrm{CE}$ & $\begin{array}{l}\text { In vivo \& In } \\
\text { vitro }\end{array}$ & $25 \mathrm{mg} / \mathrm{ml}$ & 21 days & Significant effects & Torabi et al. (2018) \\
\hline $\begin{array}{l}\text { Albendazole-chitosan } \\
\text { microsphere }\end{array}$ & $\begin{array}{l}\text { Alveolar } \\
\text { E }\end{array}$ & In vivo & $150 \mathrm{mg} / \mathrm{kg}$ & & Efficient & $\begin{array}{l}\text { Abulaihaiti et al. } \\
(2015)\end{array}$ \\
\hline $\begin{array}{l}\text { Albendazole } \\
\text { sulfoxide-loaded } \\
\text { PLGA-PEG }\end{array}$ & $\mathrm{CE}$ & In vitro & $150 \& 200 \mu \mathrm{g} / \mathrm{ml}$ & $\begin{array}{l}5-60 \\
\text { minutes }\end{array}$ & $100 \%$ & Naseri et al. (2016) \\
\hline Albendazole \& & Alveolar & In vitro & $2,000 \mathrm{~g} / \mathrm{L}$ & $48 \mathrm{hr}$. & ABZ and ABZSO showed good & Soltani et al. \\
\hline $\begin{array}{l}\text { Albendazole } \\
\text { Sulfoxide-Loaded } \\
\text { Solid Lipid NPs }\end{array}$ & $\mathrm{E}$ & & $2,500 \mathrm{~g} / \mathrm{L}$ & $72 \mathrm{hr}$. & $\begin{array}{l}\text { physicochemical properties, } \\
\text { regular release, higher } \\
\text { permeability and efficiency by } \\
\text { loading SLNPs }\end{array}$ & $(2017)$ \\
\hline $\begin{array}{l}\text { ABZ and PZQ loaded } \\
\text { solid lipid NPs (SLNs) }\end{array}$ & CE. & In vivo & --------- & $\begin{array}{l}\text { Three } \\
\text { months } \\
\text { treatment }\end{array}$ & $\begin{array}{l}\text { Treatment reduced the wet } \\
\text { weight and size of developed } \\
\text { cysts for the ABZ and PZQ } \\
\text { loaded SLNs was } 83 \% \text { and } 85 \% \text {, } \\
\text { respectively. }\end{array}$ & $\begin{array}{l}\text { Jelowdar et al. } \\
(2017)\end{array}$ \\
\hline $\begin{array}{l}\text { Ag NPs, Fe N.P.s, Cu } \\
\text { N.P.s, Si N.P.s, and Zn } \\
\text { N.P.s }\end{array}$ & $\mathrm{CE}$ & In vitro & $\begin{array}{l}0.25,0.5 \text { and } 1 \\
\mathrm{mg} / \mathrm{mL}\end{array}$ & 10-6omin & $\begin{array}{l}\text { Ag NPs showed the highest } \\
\text { effect, followed by Si NPs, } \\
\text { CuNPs, Fe NPs, ZnNPs }\end{array}$ & $\begin{array}{l}\text { Norouzi et al. } \\
(2020)\end{array}$ \\
\hline $\begin{array}{l}\text { Albendazole on Ag } \\
\text { NPs, ABZ and Ag NPs }\end{array}$ & CE & In vivo & $\begin{array}{l}\text { Mice were given } \\
\text { ABZ-loaded on } \\
\text { silver NPs } \\
\text { orally via a gastric } \\
\text { tube at a dose of } \\
100 \mathrm{mg} / \mathrm{kg} / \mathrm{d}\end{array}$ & 8 weeks & $\begin{array}{l}\text { ABZ-loaded NPs showed high } \\
\text { drug efficacy in experimentally } \\
\text { infected mice, with minimum } \\
\text { histopathological alterations, }\end{array}$ & Nassef et al. (2019) \\
\hline $\begin{array}{l}\text { Chitosan-Curcumin } \\
\text { Nanoparticles }\end{array}$ & $\mathrm{CE}$ & In vitro & $\begin{array}{l}0.25,0.05,1,2 \text {, and } \\
4 \mathrm{mg} / \mathrm{mL} \text {, }\end{array}$ & $\begin{array}{l}\text { for } 5,10,20, \\
30, \text { and } 60 \\
\text { min }\end{array}$ & $\begin{array}{l}\text { Mortality \% rate } 68 \% \text { in } \\
4 \mathrm{mg} / \mathrm{mL} \text { concentration }\end{array}$ & $\begin{array}{l}\text { Napooni et al. } \\
(2019, b)\end{array}$ \\
\hline Gold NPs & CE & In vitro & $\begin{array}{l}250,500,1000,2000 \\
\text { and } 4000 \mu \mathrm{g} / \mathrm{mL}) \text {. }\end{array}$ & $\begin{array}{l}5,10,20,30 \\
\text { and } 60 \mathrm{~min} .\end{array}$ & $\begin{array}{l}4000 \mu \mathrm{g} / \mathrm{mL} \text { of gold NPs killed } \\
76 \% \text { of protoscoleces in } 60 \text { min }\end{array}$ & $\begin{array}{l}\text { Napooni et al. } \\
(2019, a)\end{array}$ \\
\hline $\begin{array}{l}\text { Zinc oxide } \\
\text { Nanoparticles } \\
\text { ZnO- N.P.s }\end{array}$ & $\mathrm{CE}$ & In vitro & $\begin{array}{l}\text { concentration of } \\
50,100 \text { and } 150 \\
\mathrm{mg} / \mathrm{ml}\end{array}$ & $\begin{array}{l}10,30 \text { and } 60 \\
\text { minutes }\end{array}$ & $\begin{array}{l}\text { The mortality percentage of } 50 \\
\mathrm{mg} / \mathrm{ml} \mathrm{ZnO} N \mathrm{Ns} \text { is } 19.6 \% \text { of } \\
\text { protoscolices at } 10 \text { minutes. }\end{array}$ & $\begin{array}{l}\text { Norouzi et al. } \\
(2019)\end{array}$ \\
\hline $\begin{array}{l}\text { Albendazole-lipid } \\
\text { nanocapsule }\end{array}$ & $\mathrm{CE}$ & In vivo & Dose of $5 \mathrm{mg} / \mathrm{kg}$. & $\begin{array}{l}\text { Daily for } 30 \\
\text { days by an } \\
\text { intragastric } \\
\text { tube. }\end{array}$ & $\begin{array}{l}\text { ABZ-LNCs exhibited greater } \\
\text { chemoprophylactic efficiency } \\
\text { than ABZ administered orally to } \\
\text { mice. In addition, the treated } \\
\text { group didn't show any cyst. }\end{array}$ & $\begin{array}{l}\text { Ullio Gamboa et } \\
\text { al. (2019) }\end{array}$ \\
\hline $\begin{array}{l}\text { Albendazole sulfoxide } \\
\text { (ABZ-SO)-loaded } \\
\text { chitosan-PLGA NPs }\end{array}$ & CE & In vivo & $\begin{array}{l}\text { A daily dose of } 10 \\
\mathrm{mg} / \mathrm{kg}\end{array}$ & 45 days & $\begin{array}{l}\text { the therapeutic influence of } \\
\text { ABZ-SO-loaded CS-PGLA NPs } \\
\text { in the weight and volume of } \\
\text { cysts were statistically } \\
\text { significant compared with the } \\
\text { control group }\end{array}$ & $\begin{array}{l}\text { Darvishi et al. } \\
(2020)\end{array}$ \\
\hline $\begin{array}{l}\text { Zirconium Oxide } \\
\left(\mathrm{ZrO}_{2}\right)\end{array}$ & CE & In vitro & $\begin{array}{l}\text { 250, 500, 1000, } \\
2000 \text {, and } 4000 \mu \mathrm{g} / \\
\mathrm{ml})\end{array}$ & $60 \mathrm{~min}$. & $\begin{array}{l}1000,2000 \text {, and } 4000 \mu \mathrm{g} / \mathrm{ml} \\
\text { were significantly effective in } \\
\text { the killing of protoscoleces. }\end{array}$ & Ibrahim (2020) \\
\hline $\begin{array}{l}\mathrm{TiO}_{2} \text { Nanoparticles } \\
\text { and Echinometra } \\
\text { mathaeis gonad } \\
\text { extracts }\end{array}$ & $\mathrm{CE}$ & $\begin{array}{l}\text { In vivo and } \\
\text { invitro }\end{array}$ & $\begin{array}{l}15 \mu \mathrm{g} / \mathrm{ml} \text { gonad } \\
\text { extract }+\mathrm{TiO}_{2} \\
\text { Nanoparticles }\end{array}$ & $60 \mathrm{~min}$. & $\begin{array}{l}\text { Killed } 84 \% \text { of the treated } \\
\text { protoscolices }\end{array}$ & $\begin{array}{l}\text { Navvabi et al. } \\
(2019)\end{array}$ \\
\hline
\end{tabular}




\begin{tabular}{|c|c|c|c|c|c|c|}
\hline copper NPs (CuNPs) & CE & $\begin{array}{l}\text { In vitro and } \\
\text { ex vivo }\end{array}$ & $\begin{array}{l}\text { CuNPs } 250,500 \text {, } \\
\text { and } 750 \mathrm{mg} / \mathrm{mL} \\
\text { separately and with } \\
\text { albendazole of } 200 \\
\mathrm{mg} / \mathrm{mL}\end{array}$ & $5-60 \mathrm{~min}$ & $\begin{array}{l}\text { The mortality proportion of } \\
\text { protoscoleces was } 100 \% \text { after } 10 \\
\text { min of incubation with } 750 \\
\text { mg/mL of CuNPs and with } \\
\text { albendazole }\end{array}$ & $\begin{array}{l}\text { Ezzatkhah et al. } \\
(2021)\end{array}$ \\
\hline $\begin{array}{l}\text { Silver Nanoparticles } \\
\text { Ag NPs }\end{array}$ & CE & In vitro & $\begin{array}{l}\text { AgNPs } \\
0.05,0.1 \\
0.2,0.3 \\
0.4 \mathrm{mg} / \mathrm{ml}\end{array}$ & $\begin{array}{l}\text { From 10-210 } \\
\text { min }\end{array}$ & $\begin{array}{l}\text { The percentage of mortality was } \\
100 \% \text { after } 2 \text { hr.of incubation } \\
\text { with AgNPs } 0.4 \mathrm{mg} / \mathrm{l} \text {. The } \\
\text { effects were dose and time- } \\
\text { dependent }\end{array}$ & Jalil et al. (2021) \\
\hline
\end{tabular}

Nanoparticles are essential for medical uses owing to their exceptional characters, for example, large surface to mass proportion, their quantum structures, and abilities to adsorb and transport other compounds (drugs, probes, and protein).

Presently, metal NPs have broad and diverse applications in catalysis, electronics, biosensing, photonics, cosmetics, ecological cleanup, photo- imaging, and drug transport (Nath et al. 2013; Singh et al. 2016). Studies for developing the most effective and biodegradable green techniques for metal NPs are in progress. Green production of metal NPs possesses many advantages, such as simplicity, cleanness, effectiveness, safety, and cheapness. They use biological sources (plants, fungi, algae, besides microorganisms) to reduce and stabilize function (Mukherjee et al. 2012, 2014).

Moreover, NPs are dependable as a medication for the treatment of different diseases because of their antimicrobial effects. They have been proved to express promising activities against bacteria, viruses, and parasites (Jebali and Kazemi 2013).

Presently, metal NPs, mainly AuNPs and AgNPs, are applicable in the therapy of many diseases, like malignancy, diabetics mellitus, Parkinson's, Alzheimer's, HIV/AIDS, arthritis, hepatitis, cirrhosis, spinal cord injury, tuberculosis, and cardiovascular illnesses, because of their optoelectronic and physicochemical properties (Patra et al. 2015). Moreover, Aly et al. (2018) stated that silica-coated NPs with polyclonal antibodies improved Nano-sandwich ELISA sensitivity and specificity for diagnosing Toxoplasma gondii in sera and urine of patients owing to their high surface to volume proportions and crystallographic surface structure.

With respect to vaccine production, NPs show many advantages in comparison with conventional vaccines and adjuvants. They improve the solubility of hydrophobic antigens, have fewer adverse effects post-vaccination, give a sustainable controlled release of the prepared antigens, target the lymph nodes or reticuloendothelial tissues directly, and require smaller volumes and fewer doses (Dobrovolskaia et al. 2016). Nanovaccines and nanoadjuvants can be administered separately or collectively in a single shot to minimize the required doses. Nanovaccines can be given by diverse routes, which offer more flexibility, making them ideal for veterinary medicine applications, especially if many birds or animals need to be vaccinated (El-Sayed and Kamel 2018; Kamel et al. 2019). Nanotechnology aids the NPs to target the immune system specifically (in vaccine preparation), or to avoid its stimulation (in other medical applications)
(Dobrovolskaia et al. 2016). Nanoparticles can deliver different compounds via endocytosis, for instance, drugs, chemotherapeutic agents, and imaging substances. Also, biological materials like antigens, antibodies, RNA, or DNA could be delivered. They can even be depended on to deliver light and heat to their target cells when required (El-Sayed and Kamel 2020).

In Nanoparticles toxicity, which was raised from its high production and exposure of humans, recent results showed that NPs could be accumulated in vital organs such as the heart, liver, spleen, kidneys, and brain after ingestion or dermal contact. Nevertheless, scarce information is known concerning the toxicity mechanisms responsible for harmful/toxic effects of nanoparticles. In vitro and in vivo investigations pointed out that NPs could induce the creation of reactive oxygen species (ROS), which is a principal mechanism of their toxicity. ROS production leads to oxidative stress, inflammation, and subsequent destruction of proteins, cell membranes, and DNA. At the same time, ROS production induced by NPs is organized by size, shape, surface, composition, solubility, aggregation, and the route of NPs uptake (Sengul and Asmatulu 2020).

The Organization for Economic Cooperation and Development (OECD 2002) have recommended oral toxicity tests, eye irritation, skin toxicity, and lethal Dose 50 to assess acute in vivo toxicity of nanomaterials. In vivo toxicity studies include many parameters like dose, route of administration, metabolism, excretion, and immune reactions, which are also highlighted. The toxic effects of NPs on human health are significantly increasing their global recognition. Therefore, the ongoing nanotoxicology researches to investigate the biological pathways taken by NPs and induced toxic effects have increased noticeably during the last few years (Ashajyothi and Chandrakanthb 2019).

The absence of official regulations regarding nanomedicines and nanomaterial manufacture for clinical applications is considered a global issue (Foulkes et al. 2020). On the other hand, several nanomaterials and nanotechnologies have already been approved and organized in the clinical trials for different drugs, like antifungals, anticancer drugs, and pain management agents (Anselmo and Mitragotri 2019).

\section{Protoscolicidal activity of Nanoparticles}

Several researchers studied the protoscolicidal effects of biogenic NPs against E. granulosus within in vitro and in vivo models. Mahmoudvand et al. (2014) investigated 
protoscolicidal effects of selenium (Se) NPs, which were produced by Bacillus sp. MSh-1. Their results documented the potent protoscolicidal activity of different concentrations of Se NPs after a short period of treatment. Moreover, other researchers recommended Se NPs as an innovative therapeutic agent for the treatment of cutaneous leishmaniasis localized lesions. They proved their effects against both promastigote and amastigote of the causative agent (Leishmania major) of the disease (Beheshtia et al. 2013). With respect to cytotoxicity of selenium NPs, Shakibaie (2013) pointed out that no mortality was recorded in mice injected with $2.5,5.0$, and $10.0 \mathrm{mg} \mathrm{kg-1}$ of biogenic selenium NPs manufactured from Bacillus spp. In contrast, animals inoculated with 20 mg kg-1 of Se NPs expressed $20 \%$ deaths, with changes in biochemical and hematological parameters. Furthermore, the toxicity of biogenic Se NPs was less than that of the synthetic Se NPs, which established Bacillus sp's MSh-1 ability in converting the high poisonous Se compound to less poisonous Se NPs (Shakibaie 2013).

Furthermore, other researchers observed the ability of Se NPs in reducing Candida albicans biofilm. It was documented that Se could be coated on the surface of medical devices, which then would express activity against bacteria and fungi (Guisbiers et al. 2017). Selenium is a trace element essential for life (adult human needs $\sim 40 \mu \mathrm{g} \mathrm{Se}$ /day). However, it is poisonous at high levels, from $\mathrm{N}_{3200}$ to $6700 \mu \mathrm{g}$ Se/day (Navarro-Alarcon and Cabrera-Vique 2008).

Additionally, Rahimi et al. (2015) investigated protoscolicidal ability of biosynthesized silver NPs by Penicillium aculeatum against Cystic Echinococcosis. The findings proved that all concentrations of the AgNPs had remarkable protoscolicidal action. These investigators decided that AgNPs might be used as probable protoscolicidal because of their biodegradable source and harmlessness. Moreover, Lashkarizadeh et al. (2015) highlighted the protoscolicidal ability of amphotericin B, Ag NPs, essential oil of Foeniculum vulgare Mill, and hypertonic saline against Cystic Echinococcosis. They documented the antiparasitic activity of AgNPs. The maximum activity was observed in $4 \mathrm{mg} / \mathrm{mL}$, leading to a mortality percentage of $71.6 \%$ of protoscoleces after one hour of the treatment period.

Furthermore, Ag NPs could reduce the toxic effects of albendazole, the drug of choice for hydatid disease treatment. These toxic effects of albendazole may include necrosis and degeneration, steatosis, and raised serum hepatic enzymes. As a result, coating ABZ on Ag NPs could be a promising technique to increase ABZ effectiveness against Cystic Echinococcosis (Nassef et al. 2019).

Another investigation pointed out that the greenish synthesized AuNPs by $P$. aculeatum displayed activity against Cystic Echinococcosis protoscoleces in in vitro model. Several concentrations of these AuNPs for different incubation times were investigated (Barabadi et al. 2017). Their findings represented a novel method in applied nanotechnology with promising results in its effects against parasites. Also, they recommended AuNPs as a probable protoscolicidal agent against E. granulosus. They explained these effects by the large surface area to volume proportion, which provided it with novel mechanical, chemical, electrical, optical, magnetic, electro-optical, and magneto-optical properties that are missing in their original substance (Barabadi et al. 2017). A recent study demonstrated remarkable protoscolicidal effects of AuNPs. These gold NPs can be considered as an alternative treatment for Cystic Echinococcosis, eliminating side effects associated with chemical drugs (Napooni et al. 2019a).

Moreover, albendazole and Praziquantile coated solid lipid NPs represent appropriate carriers for these drugs. It is more effective than free albendazole and Praziquantile for CE's chemoprophylaxis treatment in the mouse model. This makes this compound a candidate for further investigations involving clinical practice (Jelowdar et al. 2017).

In a previous research, albendazole's loaded chitosan microspheres (ABZCS-MPs) activity as a novel carrier in experimental mice inoculated with E. multilocularis was assessed. ABZ-CSMPs showed higher absorption and better-quality bioavailability of $\mathrm{ABZ}$ in treating this infection in experimentally infected murine compared to the group given liposome-albendazole and albendazole drugs. As a result, ABZ-CS-MPs are considered as excellent applicant for treating Alveolar Echinococcosis caused by E. multilocularis (Abulaihaiti et al. 2015).

Another recent study pointed out that chitosan-curcumin NPs exhibited scolicidal activities, which suggested them as appropriate anti-protoscoleces agents (Napooni et al. 2019b). According to Torabi et al. (2018), chitosan albendazole (ChABZ) and chitosan praziquantel (ChPZQ) nanoparticles are more effective than albendazole and praziquantel against hydatid cyst disease in in vitro and in vivo models. According to their findings, a significant reduction in the number of hydatid cysts was detected in the murine group inoculated with ChABZ and ChPZQ NPs in therapeutic and chemoprophylactic designs. Moreover, these researchers demonstrated that ChPZQ NPs were more efficient than ChABZ in destroying the micro hydatid cysts. This may be attributed to the ChPZQ NPs smaller size and high stability than ChABZ NPs (Torabi et al. 2018).

In a recent in vivo study, Darvishi et al. (2020) demonstrated the activity of ABZ-sulfoxide-loaded chitosan-PGLA NPs produced by nanoprecipitation. According to this study, remarkable therapeutic effects in the weight and size of the treated cysts compared to those of the control group were observed. They concluded that ABZ-sulfoxide-loaded chitosan-PGLA NPs could improve the hydatid cyst disease treatment in the murine model. Similarly, Ibrahim (2020) investigated several levels of $\mathrm{ZrO}_{2}$ NPs against the protoscoleces of E. granulosus. This study revealed that 1000, 2000, and $4000 \mu \mathrm{g} / \mathrm{ml}$ of $\mathrm{ZrO}_{2}$ NPs were significantly efficient in killing the parasite after 60 minutes of incubation.

Furthermore, albendazole sulfoxide loaded with solid lipid NPs were produced and examined in vivo experiments against Echinococcosis (Ahmadnia et al. 
2013). According to this study, cysts in treated mice were reduced in size and weight. Also, the cysts in animals treated with albendazole sulfoxide loaded with lipid NPs showed intensive ultra-structural changes. These results proved the destructive activity of the compound against the parasite (Ahmadnia et al. 2013). The microtriches structures, functions of which were related to nutrition, were shortened or even lost in many treated hydatid cysts, suggesting that the E. granulosus reacted to adverse environments by reducing the absorption membrane area (Ahmadnia et al. 2013).

Various mechanisms proposed for antiparasitic activity of NPs have been highlighted in the literature, including apoptosis induction. Naseri et al. (2016) assessed in vitro apoptotic activities of albendazole sulfoxide and albendazole sulfoxide-loaded poly (lactic-co-glycolic acid) (PLGA)-PEG as an innovative nano polymeric particle against protoscoleces. They showed that ABZs and ABZsloaded PLGA-PEG were able to stimulate cell death of protoscoleces with the oligonucleosomal DNA fragmentation, which indicates the existence of late stages in apoptosis. These apoptotic activities of ABZs on protoscoleces were evaluated by caspase-3 mRNA expression of the E. granulosus genome. Similarly, it was noticed that albendazole and albendazole sulfoxide loading solid lipid NPs exhibited good physicochemical characteristics and controlled releasing by using solid lipid NPs as drug delivery carriers (Soltani et al. 2017). These workers proposed that such materials are useful for the treatment of Cystic Echinococcosis (Table 2).

Cystic Echinococcosis (CE) is still a neglected disease, for which the approved treatment is the use of Benzimidazole. This medication displays a parasitostatic, instead of parasiticidal, activity on hydatid cyst disease with low bioavailability. Consequently, many trials were performed to improve its solubility, absorption, and bioavailability. These experiments aimed at boosting the drug activity through NPs, resulting in accumulative intra-hydatid cystic drug levels (Siles-Lucas et al. 2018). Shnawa (2018) also reviewed several published articles related to biogenic NPs as potential agents against hydatid cyst disease and applied a Nano-carriers medication delivery system that hopefully extends the treatment options further.

In contrast, the main concern regarding use of nanoparticles is their toxicity; thus, the cytotoxicity issue of these nanoparticles should be highlighted. Besides, more studies are required to investigate the effects of these nanoparticles and their mechanisms of action as a treatment option for the CE, particularly in animal models and clinical management (Albalawi et al. 2020).

\section{Conclusion}

Hydatid cyst disease is a life-threatening zoonotic problem that results from the metacestodes of $E$. granulosus infection with limited treatment options. The standard treatment for CE is the surgical operation. However, one of the major problems following surgery is the recurrence of the infection owing to spilage of the hydatid fluid. Up to now, no effective drugs and scolicidal agents are available. The only synthetic chemical drug licensed for human treatment is Benzimidazole, which has a therapeutic efficacy of over $50 \%$, underlining the need for novel drug delivery systems. Also, this medication is known to have a parasitostatic effect instead of parasitocidal activity against E. granulosus, with limited bioavailability and severe adverse effects. Therefore, there is a crucial necessity to progress an innovative and efficient anti-hydatid agent.

Based on the results obtained from several in vitro and in vivo studies, NPs could be considered as an up-andcoming candidate and an alternative $\mathrm{CE}$ treatment resource. The most of the NPs tested for CE treatment were metal NPs, metal oxide NPs, and polymeric NPs. NPs are currently receiving much attention in research concerning Echinococcosis, but their safety is still questionable.

Consequently, the cytotoxicity of these NPs should be highlighted in future investigations. Besides, mechanisms of the cellular and molecular action of these NPs against hydatid cyst disease need to be explained. These may give a new approach in the NPS aspect and perhaps present a chance for manipulating a novel and more efficient drug for hydatid cyst disease.

\section{REFERENCES}

Abdulla RG et al., 2020. Molecular characterization of fertile hydatid cysts from the liver of the sheep and cows and associated environmental influence factors. Iraqi Journal of Veterinary Sciences 34: 321-327.

Abulaihaiti $\mathrm{M}$ et al., 2015. Efficacy of albendazole chitosan microsphere-based treatment for Alveolar Echinococcosis in mice. PLoS Neglected Tropical Diseases 9: eooo3950.

Adas G et al., 2009. Use of albendazole sulfoxide, albendazole sulfone, and combined solutions as scolicidal agents on hydatid cysts (in vitro study). World Journal of Gastroenterology 15: 112-116.

Aditya NP et al., 2013. Advances in nanomedicines for malaria treatment. Advances in Colloid and Interface Science 201-202: 1-17.

Ahmad P et al., 2003. Extracellular biosynthesis of silver nanoparticles using the fungus Fusarium oxysporum. Colloids and Surfaces B: Biointerfaces 28: 313-318.

Ahmadnia S et al., 2013. In vivo evaluation of the efficacy of albendazole sulfoxide and albendazole sulfoxide loaded solid lipid nanoparticles against hydatid cyst. Experimental Parasitology 135: 314-319.

Alanazi FK et al., 2010. Biopharmaceutical applications of nanogold. Saudi Pharmaceutical Journal 18: 179-193.

Albalawi AE et al., 2020. High potency of organic and inorganic nanoparticles to treat Cystic Echinococcosis: An evidence-based review. Nanomaterials 10: 2538.

Albi A et al., 2002. Severe hypernatremia after hypertonic saline irrigation of hydatid cysts. Anesthesia and Analgesia 95: 1806-1808. 
Almalki E et al., 2017. In vitro effectiveness of Curcuma longa and Zingiber officinale extracts on Echinococcus protoscoleces. Saudi Journal of Biological Sciences 24: 90-94.

Alving CR et al., 1978 Therapy of Leishmaniasis: Superior efficacies of liposome-encapsulated drugs. Proceedings of the National Academy of Sciences of the United States of America 75: 2959- 2963.

Aly I et al., 2018. Advantages of bioconjugated silicacoated nanoparticles as an innovative diagnosis for human Toxoplasmosis. Acta Tropica 177: 19-24.

Ammann RW and Eckert J, 1996. Cestodes: Echinococcus. Gastroenterology Clinics of North America 25: 655689.

Anselmo AC and Mitragotri S, 2019. Nanoparticles in the clinic: An update. Bioengineering and Translational Medicine 4: e10143.

Aronson JKMA, 2016. Meyler's Side effects of drugs. The International Encyclopedia of Adverse Drug Reactions and Interactions. 16th Edition. Elsevier BV, pp: 102-110.

Ashajyothi C and Chandrakanth RK, 2019. A pilot toxicology study of biogenic silver nanoparticles: In vivo by intraperitoneal and intravenous infusion routes in rats. Journal of Experimental Nanoscience 14: 89-106.

Barabadi $\mathrm{H}$ et al., 2017. Green chemical synthesis of gold nanoparticles by using Penicillium aculeatum and their scolicidal activity against hydatid cyst protoscolices of Echinococcus granulosus. Environmental Science and Pollution Research 24: 5800-5810.

Begum NA et al., 2009. Biogenic synthesis of $\mathrm{Au}$ and Ag nanoparticles using aqueous solutions of Black Tea leaf extracts. Colloids and Surfaces B: Biointerfaces 71: 113-118.

Beheshtia $\mathrm{N}$ et al., 2013. Efficacy of biogenic selenium nanoparticles against Leishmania major: In vitro and in vivo studies. Journal of Trace Elements in Medicine and Biology 27: 203-207.

Benyan AKZ et al., 2013. Second reported case of multilocular hydatid disease in Iraq. Qatar Medical Journal 5: 28-29.

Brunetti E et al., 2010. Expert consensus for the diagnosis and treatment of Cystic and Alveolar Echinococcosis in humans. Acta Tropica 114(1): 1-16.

Chanda NR et al., 2011. An effective strategy for the synthesis of biocompatible gold nanoparticles using cinnamon phytochemicals for phantom CT imaging and detection of cancerous cells. Pharmaceutical Research 28: 279-291.

Darvishi MM et al., 2020. Evaluation of the efficacy of albendazole sulfoxide (ABZ-SO)-loaded chitosanPLGA nanoparticles in the treatment of Cystic Echinococcosis in laboratory mice. Parasitology Research 119: 4233-4241.

Dobrovolskaia MA et al., 2016. Current understanding of interactions between nanoparticles and the immune system. Toxicology and Applied Pharmacology 299: 78-89.
Durán $\mathrm{N}$ et al., 2011. Mechanistic aspect in the biogenic synthesis of extracellular metal nanoparticles by peptides, bacteria, fungi, and plants. Applied Microbiology and Biotechnology 90: 1609-1624.

Dutta PP et al., 2017. Antimalarial silver and gold nanoparticles: Green synthesis, characterization, and in vitro study. Biomedicine and Pharmacotherapy 91: 567-580.

Eckert J et al., 200o. Echinococcosis: An emerging or reemerging zoonosis? Intnational Journal of Parasitology 30: 1283-1294.

Elissondo MC et al., 2008. Efficacy of thymol against Echinococcus granulosus protoscoleces. Parasitology International 57: 185- 190.

El-Sayed A and Kamel M, 2018. Advanced applications of nanotechnology in veterinary medicine. Environmental Science and Pollution Research 10: 114

El-Sayed A and Kamel M, 2020. Advances in nanomedical applications: Diagnostic, therapeutic, immunization, and vaccine production. Environmental Science and Pollution Research 27: 19200-19213.

Eriksen C and Agopian VG, 2017. The management of Echinococcal cyst disease of the liver. In: Current Surgical Therapy. 12th Edition. Cameron and Cameron; pp: 343-349.

Evrard B, 2002. Oral bioavailability in sheep of albendazole from a suspension and from a solution containing hydroxypropyl-bcyclodextrin. Journal of Controlled Release 85: 45-50.

Ezzatkhah F et al., 2021. Copper nanoparticles: Biosynthesis, characterization, and protoscolicidal effects alone and combined with albendazole against hydatid cyst protoscolece. Biomedicine and Pharmacotherapy 136: 111257.

Foulkes $\mathrm{R}$ et al., 2020. The regulation of nanomaterials and nanomedicines for clinical application: Current and future perspectives. Biomaterials Science 8(17): 4653-4664.

Fritsche TR and Pritt PS, 2017. Medical parasitology. Chapter 63. In: Henry's Clinical Diagnosis and Management by Laboratory Methods, 23 Edition. Elsevier Inc.

Galindo M et al., 2008. Echinococcus granulosus: Cellular territories and morphological regions in mature protoscoleces. Experimental Parasitology 11: 524-533.

Gollackner B et al., 200o. Radical surgical therapy of abdominal cystic hydatid disease: Factors of recurrence. World Journal of Surgery 24: 717-721.

Guisbiers $G$ et al., 2017. Inhibition of Candida albicans biofilm by pure selenium nanoparticles synthesized by pulsed laser ablation in liquids. Nanomedicine: Nanotechnology, Biology and Medicine 13: 1095-1103.

Hemphill A et al., 2007. Innovative chemotherapeutical treatment options for Alveolar and Cystic Echinococcosis. Parasitology 134: 1657-1670.

Horton RJ, 1989. Chemotherapy of Echinococcus infection in man with albendazole. Transactions of The Royal Society of Tropical Medicine and Hygiene 83: 97-102. 
Horton RJ, 1997. Albendazole in treatment of human Cystic Echinococcosis: 12 years of experience. Acta Tropica 64: 79-93.

Ibrahim AAJ, 2020. Scolicidal activity of zirconium oxide $\left(\mathrm{ZrO}_{2}\right)$ nanoparticles against protoscolices of hydatid cysts. Indian Journal of Forensic Medicine and Toxicology 14: 409.

Iravani S, 2011. Green synthesis of metal nanoparticles using plants. Green Chemistry 13: 2638-2650.

Jalil PJ et al., 2021. Silver nanoparticles: Green synthesis, characterization, blood compatibility, and protoscolicidal efficacy against Echinococcus granulosus. Pakistan Veterinary Journal http://dx.doi.org/10.29261/pakvetj/2021.039.

Jebali A and Kazemi B, 2013. Nano-based antileishmanial agents: Toxicological study on nanoparticles for future treatment of cutaneous Leishmaniasis. Toxicology In Vitro 27(6): 1896-1904.

Jelowdar A et al., 2017. Efficacy of combined albendazol and praziquntel and their loaded solid lipid nanoparticles components in chemoprophylaxis of experimental hydatidosis. Asian Pacific Journal of Tropical Biomedicine 7: 549-554.

Junghanss $\mathrm{T}$ et al., 2008. Clinical management of Cystic Echinococcosis: State of the art, problems, and perspectives. The American Journal of Tropical Medicine and Hygiene 79: 301-311.

Kamel $\mathrm{M}$ et al., 2019. Foot-and-mouth disease vaccines: Recent updates and future perspectives. Archieves of Virology 164(6): 1501-1513.

Kaushik $\mathrm{N}$ et al., 2010. Biological synthesis of metallic nanoparticles. Nano medicine: Nanotechnology, Biology and Medicine 6: 257-262.

Kohansal MH et al., 2017. Natural products applied against hydatid cyst protoscolices: A review of past to present. Acta Tropica 176: 385-394.

Kuster $\mathrm{T}$ et al., 2014. Activities of fenbendazole in comparition with albendazole against Echinococcus multilocularis metacestodes in vitro and in a murine infection model. International Journal of Antimicrobial Agent 43: 335-342.

Lashkarizadeh MR et al.,2015. Comparison of scolicidal effects of amphotricin B, silver nano $\neg$ particles, and foeniculum vulgare mill on hydatid cysts protoscoleces. Iran Jounal of Parasitology 10: 206-212.

$\mathrm{Li} \mathrm{G}$ et al., 2012. Fungus mediated green synthesis of silver nanoparticles using Aspergillus terreus. International Journal of Molecular Sciences 13: 466476.

McManus DP et al., 2003. Echinococcosis. Lancet 362: 1295- 1304.

Mahmoudvand $\mathrm{H}$ et al., 2014. Scolicidal effects of biogenic selenium nanoparticle against protoscolices of hydatid cysts. International Journal of Surgery 12: 399-403.

Moro P and Schantz PM, 2009. Echinococcosis: A review. International Journal of Infectious Diseases 13: 125-133.

Mühlebach S, 2018. Regulatory challenges of nanomedicines and their follow-on versions: A generic or similar approach? Advanced Drug Delivery
Reviews 131: 122-131.

Mukherjee P et al., 2002. Extracellular synthesis of gold nanoparticles by the fungus. Chembiochem 3: 461463.

Mukherjee S et al., 2014. Potential theranostics application of biosynthesized silver nanoparticles (4in-1 system). Theranostics 4: 316-335.

Mukherjee S et al., 2012. Green chemistry approach for the synthesis and stabilization of biocompatible gold nanoparticles and their potential applications in cancer therapy. Nanotechnology 23: 455103.

Napooni S et al., 2019a. Lethal effects of gold nanoparticles on protoscolices of hydatid cyst: In vitro study. Comparative Clinical Pathology 28: 143-150.

Napooni S et al., 2019b. Scolicidal effects of chitosancurcumin nanoparticles on the hydatid cyst protoscoleces. Acta Parasitologica 64:367-375.

Naseri $\mathrm{M}$ et al., 2016. Scolicidal and apoptotic activities of albendazole sulfoxide and albendazole sulfoxideloaded PLGA-PEG as a novel nanopolymeric particle against Echinococcus granulosus protoscoleces. Parasitological Research 115: 4595-4603.

Nassef NE et al., 2019. Evaluation of the therapeutic efficacy of albendazole-loaded silver nanoparticles against Echinococcus granulosus infection in experimental mice. Journal of Parasitic Diseases 43: 658-671.

Nath D and Banerjee P, 2013. Green nanotechnology - A new hope for medical biology. Environmental Toxicology and Pharmacology 36: 997-1014.

Navarro-Alarcon M and Cabrera-Vique C, 2008. Selenium in food and the human body: A review. Science of The Total Environment 400: 115-141.

Navvabi A et al., 2019. Combination of $\mathrm{TiO}_{2}$ nanoparticles and Echinometra mathaeis gonad extracts: In vitro and in vivo scolicidal activity against hydatid cysts. Biocatalysis and Agricultural Biotechnology 22: 101432.

Norouzi $\mathrm{R}$ et al., 2019. Scolicidal effect of zinc oxide nanoparticles against hydatid cyst protoscoleces in vitro. International Journal of Nanomedicine 4:23-28.

Norouzi R et al., 2020. Scolicidal effects of nanoparticles against hydatid cyst protoscolices in vitro. International Journal Nanomedicine 15: 1095-110o.

OECD, 2002. Test guideline 405. Acute eye irritation and corrosion. OECD guidelines for the testing of chemicals Paris, France: Organization for Economic Cooperation and Development (OECD).

Patra S et al., 2015. Green synthesis, characterization of gold and silver nano-particles and their potential application for cancer therapeutics. Materials Science and Engineering: C 53: 298-309.

Pawlowski ZS, 1997. Compendium on Cystic Echinococcosis in Africa and in Middle East countries with special reference to Morocco. Provo: Brigham Young University Print Services, 119-135.

Perez-Serrano J et al., 1994. The effects of albendazole and albendazole sulphoxide combination-therapy on Echinococcus granulosus in vitro. International Journal of Parasitology 24: 219-224. 
Pitt SC and Pitt HA, 2013. The management of Echinococcal cyst disease of the liver. In: Cameron JL and Cameron AM (editors). Current Surgical Therapy. NCBI 311.

Rahimi MT et al., 2015. Scolicidal activity of biosynthesized silver nanoparticles against Echinococcus granulosus protoscolices. International Journal of Surgery 19: 128-133.

Rai $M$ et al., 2017. Recent advances in use of silver nanoparticles as antimalarial agents. International Journal of Pharmaceutics 526: 254-270.

Rangnekar TK et al., 2007. Retention of enzymatic activity of a-amylase in the reductive synthesis of gold nanoparticles. Langmuir 273: 5700-5706.

Rausch RL, 1997. Echinococcus granulosus: Biology and Ecology. In: Compendium on Cystic Echinococcosis in Africa and Middle Eastern Countries with Special Reference to Morocco. Andersen, F. L., Ouhelli, H. and Kachani, M. (editors). Brigham Young University Print Service, Provo, UT846o2, USA.

Reddy LH and Couvreur P, 2011. Nanotechnology for therapy and imaging of liver diseases. Journal of Hepatology 55: 1461- 1466.

Roduner E, 2006. Size matters: Why nanomaterials are different. Chemical Society Reviews 35: 583-592.

Romig $\mathrm{T}$ et al., 2015. Taxonomy and molecular epidemiology of Echinococcus granulosus sensu lato. Veterinary Parasitology 213: 76-84.

Sadjjadi SM, 2006. Present situation of Echinococcosis in the Middle East and Arabic North Africa. Parasitology International 55: S197-S2O2.

Sengul AB and Asmatulu E, 2020. Toxicity of metal and metal oxide nanoparticles: A review. Environmental Chemistry Letters 18: 1659-1683.

Shakibaie M, 2013. Acute and subacute toxicity of novel biogenic selenium nanoparticles in mice. Pharmaceutical Biology 51: 58-63.

Shi $\mathrm{H}$ et al., 2016. Protoscolicidal effects of chenodeoxycholic acid on protoscoleces of Echinococcus granulosus Experimental Parasitology 167: 76-78.

Shnawa BH, 2018. Advances in the use of nanoparticles as anti-Cystic Echinococcosis agents: A review article. Journal of Pharmaceutical Research International 24: 1-14.

Shnawa BH et al., 2017. Efficacy of Cyperus rotundus rhizomes tubers extracts against protoscoleces of Echinococcus granulosus. World Journal of Pharmaceutical Research 6: 1-23.
Shuhua X et al., 2002. Augmented bioavailability and cysticidal activity of albendazole reformulated in soybean emulsion in mice infected with Echinococcus granulosus or Echinococcus multilocularis. Acta Tropica 82: 77-84.

Siles-Lucas $M$ et al., 2018. Progress in the pharmacological treatment of human Cystic and Alveolar Echinococcosis: Compounds and therapeutic targets. PLoS Neglected Tropical Diseases 12: eooo6422.

Singh P et al., 2016. Biological synthesis of nanoparticles from plants and microorganisms. Trends in Biotechnology 34: 589-599.

Soltani S et al., 2017. Evaluation of the hydatid cyst membrane permeability of albendazole and albendazole sulfoxide-loaded solid lipid nanoparticles. Jundishapur Journal of Natural Pharmaceutical Products 12: e34723.

Soares S et al., 2018. Nanomedicine: Principles, properties, and regulatory issues. Frontiers in Chemistry 6: 360 .

Thompson RCA, 1986. Biology and systematics of Echinococcus. In: "Biology of Echinococcus and Hydatid Disease". R.C.A. Thompson (editor): George Allen and Unwin, London, UK, pp: 5-43.

Tiggi A et al., 1995. Increase of serum glutamicoxaloacetic and glutamic-pyruvic transaminases in patients with hydatid cysts treated with mebendazole and albendazole. Mediterranian Journal of Infectious Parasitic Diseases 10: 85-90.

Torabi $\mathrm{N}$ et al., 2018. In vitro and in vivo effects of chitosan-praziquantel and chitosanalbendazole nanoparticles on Echinococcus granulosus metacestodes. Parasitology Research 117: 2015- 2023.

Ullio Gamboa GVU et al, 2019. Albendazole-lipid nanocapsules: Optimization, characterization and chemoprophylactic efficacy in mice infected with Echinococcus granulosus. Experimental Parasitology 198: 79-86.

Walker $\mathrm{M}$ et al., 2004. In vitro effects of nitazoxanide on Echinococcus granulosus protoscoleces and metacestodes. Journal of Antimicrobial Chemotherapy 54: 609-616.

WHO, 20o1. Working to overcome the global impact of neglected tropical diseases. First WHO report on neglected tropical diseases 2010. Available: http://www.who.int/iris/handle/10665/ 70503. 